of their rights and that they are consenting to treatments given. Form 38 will have no place in this scheme. This amendment will mean that longterm detained patients are treated as autonomous beings with the capacity to understand and make judgements about the need for medication.

\section{References}

Beauchamp, T. L. \& Childress, J. L. (1979) Principles of Biomedical Ethics, 2nd edition. Oxford University Press.
Department of Health (1990) Code Of Practice. London: HMSO.

- (1987) Mental Health Act 1983 Memorandum on Parts I to VI, VIII and X. London: HMSO.

JoNES, R. (1988) Mental Health Act Manual, 2nd Edition. London: Sweet \& Maxwell.

Meisel, A., Roth, L. H. \& Lidz, C. W. (1977) Toward a model of the legal doctrine of informed consent. American Journal of Psychiatry, 134, 285-289.

Roth, L. H., Meisel, A. \& LIDZ, C. W. (1977) Tests of competency to consent to treatment. American Journal of Psychiatry, 134, 279-284.

\title{
Response of the Mental Health Act Commission
}

The Commission welcomes the opportunity to comment on Dr Oyebode's paper. As a former medical member of the Commission, Dr Oyebode can write with authority on the frustrations felt by many Commissioners when carrying out their statutory obligations to ensure that the requirements of Section 58 of the Act are being met. His paper is particularly opportune considering the recent publication by the Law Commission of its consultation paper No. 129 (Law Commission, 1993).

Dr Oyebode argues that Section 58 does not strengthen the patient's right to consent to treatment and that the advice within the Code of Practice in respect of Form 38 is faulty in conception. He is quite correct to draw attention to the significance placed by the legislation on the certification of consent by the prescribing doctor rather than on the usual requirement that consent should be directly expressed by the patient, for example by signing a consent form.

Although the Mental Health Act does not specifcally refer to the right of the patient to signify consent, it would be unlawful for the responsible medical officer (RMO) to certify consent if consent had not been secured and signified, just as it would be unlawful to use a patient's signed consent form when true consent had been withdrawn. In giving the responsibility of certifying consent to the RMO, the law recognises the particular difficulties faced by detained mentally disordered patients. It does not deny the patient the opportunity to demonstrate consent. Indeed, without that demonstration the certificate is invalid.

The author draws attention to the absence of procedures for establishing and recording consent to medication in informal patients. Consultants could be in difficulties, however, if they accepted the assertion that "mere assent or dissent are recognised as valid decisions in this context". This may not be the position in a court of law.

DrOyebode is not completely correct in stating that Form 39 relates specifically "to a non-consenting patient whose competence and/or autonomy are compromised". It does, of course, also record the authority to administer medicines for the treatment of mental disorder to a competent patient who refuses consent where the treatment should be given.

If there is a discrepancy between the consent certified on Form 38 to a given treatment plan and the treatment plan actually being given then Commissioners are entirely correct to conclude that the recorded consent does not relate to the treatment being given and that there is prima facie evidence that the requirements of Section 58 are not being met. Dr Oyebode's advice that Commissioners should look beyond the correspondence between Form 38 and the treatment card and into the actual consent status of the patient is timely, as is the attention he draws to the latitude which current advice gives in regard to the description of treatment on Form 38. To this extent the minimal requirements suggested by the Code of Practice increase the obligation on the Responsible Medical Officer to ensure that the patient's actual consent is valid at all times.

The conclusion that the RMO's completion of Form 38 is redundant when a detained patient has signed a consent form makes many assumptions about the validity of signed consent forms and the further recommendations place more weight on formal written procedures than perhaps is warranted in a clinical situation, although a patient's rights document might be a useful additional safeguard. The Commission would be interested to learn whether Dr Oyebode's conclusions that the autonomy of detained patients would be better served by abandoning Form 38 is generally supported by the Royal College of Psychiatrists. The frequent discrepancies noted between Form 38 and the actual treatment being given do not inspire confidence that consent issues and patient autonomy generally are currently given sufficient priority.

\section{Reference}

Law Commssion (1993) Mentally Incapacitated Adults and Decision Making. Medical Treatment and Research. Consultation Paper Number 129. London: HMSO. 